\title{
Reusing Built Heritage. Design for the Sharing Economy
}

\author{
Roberto Bolici, Giusi Leali and Silvia Mirandola
}

\begin{abstract}
In the last years, the construction sector has seen a greater number of building interventions on existing assets rather than the realization of new buildings. The enhancement of urban property assets can become an opportunity both for efficient and effective building management and for the offer of innovative public and private services on the territory. With this approach, based on sustainable urban regeneration, the enhancement could be intended in many different ways such as recovery, maintenance, and reuse of abandoned or underutilized buildings. This phenomenon, present in general in building assets as a whole, is more evident in the management of the public ones. The reuse of these buildings acts as an answer to a change in the needs of the community regarding welfare, culture, and work, generating a new economic, social, and environmental value. In relation to their innovative features, the new functions related to the real dimensions of sharing are emerging, and with them a new approach to the project. The increase in these new kinds of sharing and the insufficient knowledge about design and management of the relative "box" have allowed for the development of the study entitled "Enhancement of abandoned or underutilized assets. Design for coworking." The main goal of the study was to define, within the logic of environmental technology design, the key points of this framework. This was possible thanks to the collection of data which was useful to increase the knowledge regarding the design of these places within abandoned or underutilized buildings and their management.
\end{abstract}

Keywords Coworking · Urban regeneration · Sharing economy

R. Bolici $(\varangle)$

Architecture, Built Environment and Construction Engineering-ABC Department, Politecnico di Milano, Milan, Italy

e-mail: roberto.bolici@polimi.it

G. Leali $\cdot$ S. Mirandola

Milan, Italy

(C) The Author(s) 2020

S. Della Torre et al. (eds.), Regeneration of the Built Environment

from a Circular Economy Perspective, Research for Development,

https://doi.org/10.1007/978-3-030-33256-3_29 


\section{Introduction}

The Europe 2020 Strategy of the European Union has assigned a fundamental role to cohesion policies in the socioeconomic development of the territory. The implementation of these policies requires the enhancement of a more efficient and competitive economy that is more attentive to environmental issues, including in terms of building recovery and land consumption (sustainable growth); support for employment, especially youth employment, to foster social and territorial cohesion (inclusive growth), and finally, the development of a knowledge and innovation economy (smart growth).

Strategies necessary for achieving these objectives are the optimal use of resources and financial opportunities in key economic sectors and the structuring of an integrated and coordinated approach to interventions. The synergic activation of these elements offers new opportunities for businesses and the community, boosts local development, strengthens coordination between community, national, and sectoral policies and broadly facilitates the process of territorial cohesion also through the 'activation of a partnership between local and regional actors, social partners and civil society'.

Within the scenario envisaged by the European Union, the issue of social inclusion, as a way of favoring a better and full integration of the individual within the social and economic context in which they live, is brought back, in addition to the sphere of welfare, to labor policies. For the community, employment is an indispensable prerogative for accessibility to the services and opportunities created by economic growth, in fact, through processes of inclusion and reduction of social hardship, it becomes both a recipient of interventions or services and an active agent of economic development, social life, and the well-being of a territory.

The international economic crisis characterizing the last decade has brought to the forefront the problem of unemployment, especially youth unemployment. A possible way of looking into this issue is the activation of multilateral and innovative collaborations, involving public administration, social parties, educational institutions, communities, and young people (International Labor Office 2012), for the construction of projects that facilitate youth entrepreneurship, which represents an opportunity for local businesses that can draw innovative elements from this, starting from the skills of young professionals and incorporating them into their companies.

The sustainable growth promoted by the European Union is also implemented through rational use of resources and finds in the theme of urban regeneration and therefore the reuse of real estate a wide context of experimentation.

The theme of urban regeneration in a sustainable way represents a priority aspect in the development policies of cities as it offers, on the one hand, the opportunity to trigger architectural, environmental, energy, and social redevelopment processes of urban centers, starting from the reuse of already existing real estate assets. On the other hand, there can be important social and economic consequences from the transformation of degraded urban areas into real catalysts for creativity and 
innovation. The recovery and strategic management of the abandoned heritage can significantly influence the entire "urban context due to its location in central and valuable areas and to the possible historical and artistic value, thus constituting a precious resource, not only in immediate monetary terms, but also as an element of requalification and growth for large portions of the urban fabric which could increase their value and become attractive for investment" (Baiani and Cangelli 2012).

In this scenario, the enhancement of the underutilized or disused public heritage, implemented through the reuse of that which is built, in addition to being an opportunity in economic terms and rationalization of the expenditure of local administrations, represents an opportunity to experiment regeneration interventions in urban centers. By investing in aspects such as technological innovation and environmental design, this real estate asset is the cornerstone on which to structure a broader strategy to rethink the entire city through the definition of a new network of spaces within consolidated urban fabrics and of alternative functions to those now acquired over time (Ottone et al. 2012).

By this logic, the local administrations are defining new destinations of use for the high quantity of underused or abandoned buildings to give them new value (Manzo 2007) and to respond to the changing needs of the collectivity in terms of welfare, culture, and work. With respect to the panel of possible new destinations, and in line with European labor policies, the functions connected to the performance of "collaborative" work activities linked to a sharing economy emerge due to their innovative nature. The collaborative economy does not propose "merely a new consumption model, but also an alternative way to move (carsharing), to lend (crowdfunding), to work (coworking), to learn, to travel, to be together, to eat and therefore to live" (Maineri 2013).

The "containers" of the collaborative economy therefore provide, on the one hand, a response to the need of public administration to assign a new functions and to make assets that are disposed of or underutilized their own. On the other hand, they offer emerging professionals the opportunity to use their skills in innovative work spaces that allow them to "incubate" their ideas by putting them in a system with those of others and then being able to propose them in a more competitive way to the "outside." The positive effects, following the activation of these containers for the collaborative economy, are also to be sought in the "talent gardens" provided to local companies, capable of encouraging the innovation in socioeconomic terms of the territory. 


\section{Collaborative Economy Platforms. Analysis and Study of a Growing Phenomenon}

The growing increase in collaborative work ${ }^{1}$ and the lack of knowledge in planning and management aspects have stimulated the development of the study entitled "Valorisation of abandoned or underutilized real estate assets. Design for coworking ${ }^{2}$ " (Bolici et al. 2015). The study, starting from the recognition of a wide and detailed reading of the national panorama of the sharing economy spaces and in particular of those for coworking, allowed us to extend and put systematic design and management indications in order to structure a design concept-with a management that is declinable in relation to the peculiarities of the different contexts (Fig. 1).

Currently in Italy, there is a constant increase in places where it is possible to work together, collaborating and creating a community that uses the same environment: these spaces can be identified with those for coworking, talent gardens, and Fab labs. The term coworking does not only define a physical space but refers to a real style of work-oriented toward sharing an environment, which, however, leaves users with the possibility of developing independent activities. In the talent gardens, in addition to sharing spaces and services, new ideas are formulated for the development of economic activities capable of evolving into start-ups and projects. Finally, the philosophy at the heart of Fab labs is the sharing of ideas and the promotion of sustainable technological development in order to bring innovation and technological knowledge to the territory in which the laboratory operates.

To present a cross section of the containers for a collaborative economy present at national level, the study involved a desk analysis of the dedicated platforms and of the sector literature and of questionnaires given to the space managers; the survey embraced 422 case studies, collected in a database.

$84 \%$ of the spaces analyzed were coworking, demonstrating that within the national territory, this platform is the one that best responds to market demands, anticipating lower start-up costs compared to the infrastructure of spaces that must support a Fab lab and not requesting specific managerial skills, which typical of a talent garden. The geographical distribution has shown that $65 \%$ of the collaborative economy has developed in the northern part of the national territory; specifically for coworking spaces, a high concentration was recorded in the Lombardy region (over $30 \%$ of the total), particularly in the Milan area and in its hinterland.

Given the importance in quantitative terms of coworking spaces, the research has looked closer into this new working reality from the point of view of inclusion in the local settlement system, of the location within a given architectural typology, of the type of building intervention, of the surface, of user capacity, of the functions present within the containers, and of the management models. The analysis showed that the placement of the spaces in relation to the context sees a greater presence in

\footnotetext{
${ }^{1}$ As noted by the "1st Annual Global Coworking Survey" conducted by Deskmag.

${ }^{2}$ The research project was commissioned to the UdR TEMA of the Mantua Research Laboratory of the Politecnico di Milano-Mantova Campus by PromoImpresa Borsa-Merci-Mantova Chamber of Commerce.
} 


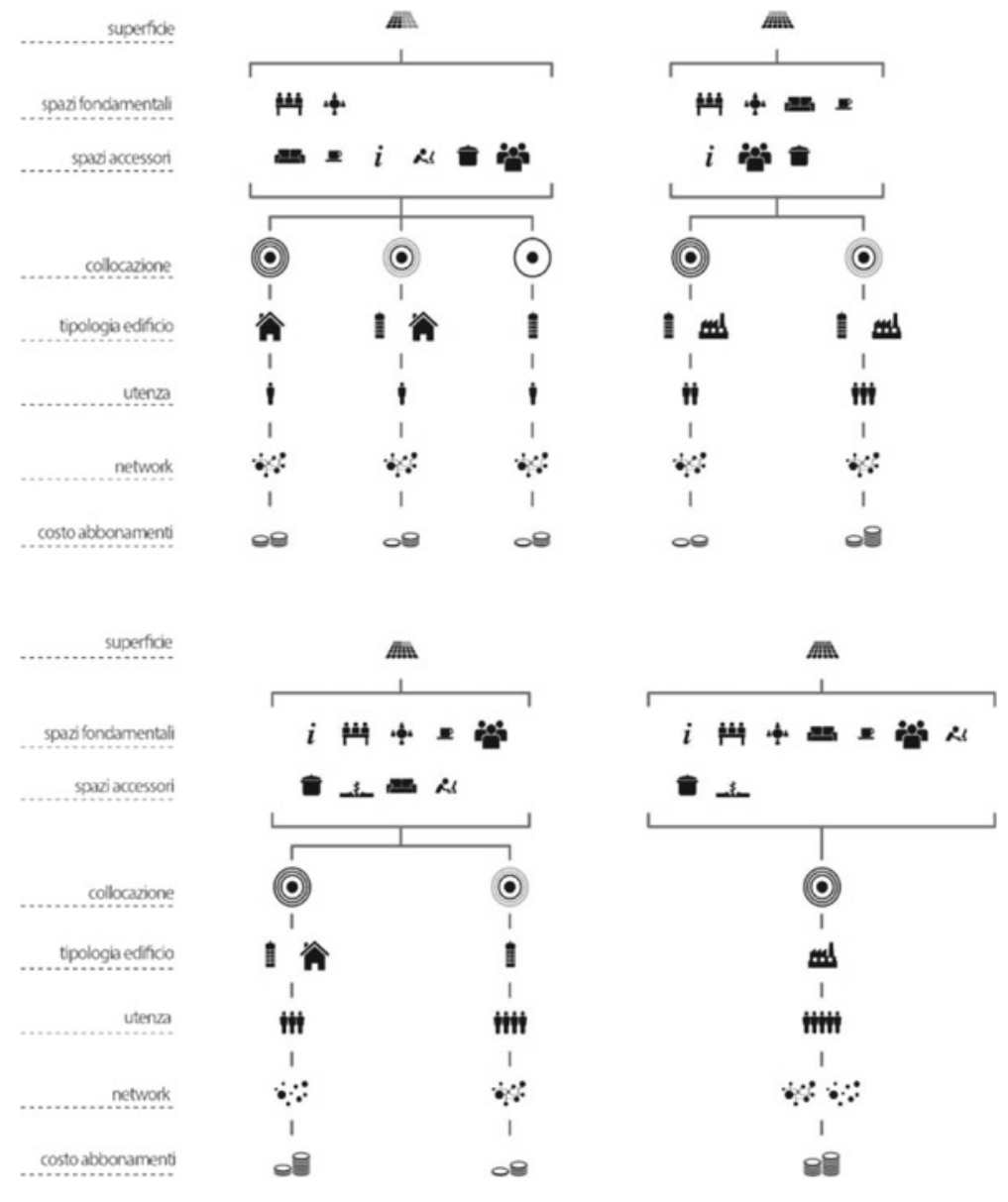

Fig. 1 Comparative matrix

the urban center $(71 \%)$, followed by the peripheral areas $(25 \%)$, while it is minimal in isolated contexts (4\%). As for buildings, the tendency to recover buildings (90\%) was recorded rather than the construction of new buildings; this observation supports the principle of sustainability at the core of the collaborative economy, which sees the redevelopment of what already exists as an opportunity to make these spaces active once more and reduce land consumption. As the coworking spaces are generally located in existing recovered structures, it was also interesting to note that around four-fifths of them refer to residential and commercial buildings with a slight prevalence of residential buildings, while only a small part is located inside industrial buildings.

The analysis showed that $72 \%$ of the containers have an area of less than $250 \mathrm{~m}^{2}$, particularly between 50 and $100 \mathrm{~m}^{2}$. Given the small surfaces, most of them can 
accommodate a small number of people (from 1 to 10); this size, while not contributing on the one hand to generating significant economies of scale, on the other hand, it does favor the creation of communities.

The essential functional spaces within the various containers surveyed have been traced back to four major categories: work spaces (meeting room, open space offices, study room, conference room), service spaces (reception entrance, kitchen), spaces for additional services (library, laboratory), and recreational spaces (refreshment area, relaxation area, outdoor space). Starting from the analysis of the existing realities, a hierarchy of these functions has been articulated based on their diffusion, which has allowed us to determine as open spaces of a coworking environment open space offices (easily adaptable and flexible spaces) that allow the users to work inside a large environment that stimulates collaboration, as opposed to a traditional office, and meeting rooms (necessary to hold meetings without disturbing other coworkers). Given the prevailing informal nature of these platforms, the relaxation areas and the refreshment areas (spaces equipped to encourage dialog between coworkers) are fundamental for the creation of an environment that favors socialization and sharing. Complementary to these spaces are the study rooms and private offices, or spaces intended exclusively for certain users, and the congress rooms structured to host presentations and events. In a smaller number of cases, the presence of a room equipped as a kitchen and spaces for library and laboratories was detected; in this case, it is a hybrid coworking platform, with features more common to the Fab labs.

With respect to the theme of space management, it was found that the manner is exclusively private, more than a quarter of the platforms analyzed adhere to a network and in only $10 \%$ of the cases analyzed, in order to make use of the spaces, a membership is required. Particularly, joining a network allows for the community of a coworking environment to increase exponentially by creating an ecosystem of relationships in which proposals are activated and contaminations develop in the entrepreneurial and professional sphere, particularly at the level of freelancers and small work teams. The advantages of belonging to a network are generally the use of a brand, having basic advice available for management and presence on the media and on social media, increasing the visibility and knowledge of the structure toward possible coworkers present in the territory.

The subscription costs that a user incurs per year to use the spaces are on average between $€ 1000$ and 3000 ; the peaks noted refer to platforms that do not adhere to the network, since adherence to networks generally leads to price control.

To obtain a cross section of the analyzed realities and to provide a methodological direction for the design of coworking spaces, a comparative matrix has been elaborated which has systemized the information concerning the functions with the surfaces, the location, the types of buildings hosting these activities, the number of users that can be hosted, network membership, and, finally, the annual cost of subscriptions. The reading of the matrix, consisting of four sections defined according to the extension of the surfaces of the collaborative platforms and their geographical location, has revealed that the spaces with reduced dimensions $\left(0-250 \mathrm{~m}^{2}\right)$ find a preferential position in central areas, peripheral areas, and in isolated contexts, within 
residential and commercial building types. Since the platforms are small, they consequently have a reduced capacity and rely on existing networks to develop their business. The subscription cost is lower for spaces located in the suburbs or isolated areas. The spaces with medium-small surfaces $\left(250-500 \mathrm{~m}^{2}\right)$ find a counterpart only in the center and on the outskirts where they are located within commercial and industrial buildings. Also in this case, joining a network is a characterizing element. Access to spaces has a higher cost in peripheral structures than in central ones. The realities that have medium-large surfaces $\left(500-1000 \mathrm{~m}^{2}\right)$ are located in central and peripheral contexts, mainly occupying buildings for commercial and residential use and increasing the number of users that can be hosted. In this category, joining networks is not widespread. There is a noticeable difference in the cost of subscription between central and peripheral facilities. Platforms with large surfaces (more than $1000 \mathrm{~m}^{2}$ ) are generally located in central areas within disused industrial buildings and provide a high number of workstations. The cost of subscriptions is medium-high and, as in the previous class, network membership is not a characterizing element. Finally, reading the information in a transversal manner, a number of elements characterizing the entire system emerge, such as the direct relationship between the increase in number of functions and the increase in surface area and between users and surface area, the preferential location in urban centers, the commercial building as prevalent building typology, the frequency of adhesion to a network, the proportion between the cost of the subscriptions proposed to the coworkers and the dimensions of the surfaces, and therefore of the functions offered, and the greater cost for access to platforms located in historical centers.

\section{Proposal for the Definition of a Project-Management Concept}

The analysis of the spaces present in the analyzed collaborative platforms made it possible to define the reciprocal relationships between the functions present in a coworking environment. The study of the relationships between the spaces has allowed us to conduct a synoptic reading of the different elements that structure the containers for a collaborative economy, and to define a concept of articulation of spaces, paths, and use of services over time (temporary, Fig. 2, medium, Fig. 3, and long, Fig. 4, term).

The spaces destined to be used by users on a temporary basis (e.g., daily use) are located near the entrance and are inserted along a path that allows users to reach only certain functions within the coworking system (open space office, refreshment area, services, conference room, and meeting room). Users who use spaces in a more structured way, but that are limited in time (e.g., weekly-monthly use), can benefit from additional services according to a growing level of accessibility to spaces (flexible open-space work area, kitchen, relaxation area), to the external space, to the library, and to the laboratory. Finally, users who use the space with greater 


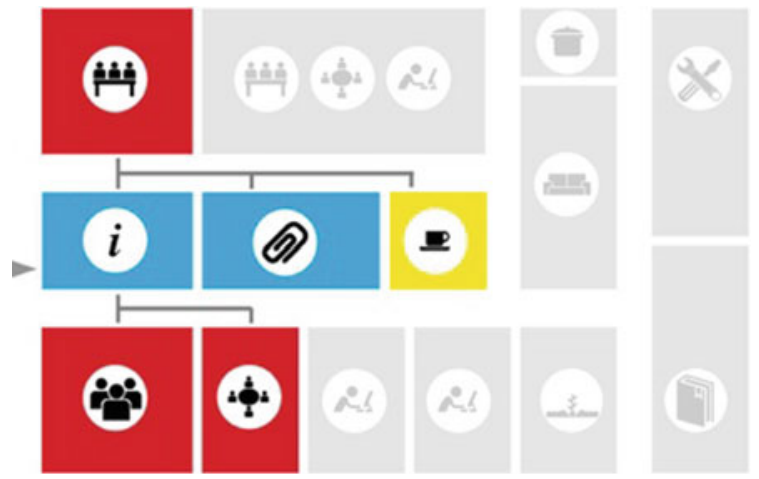

Fig. 2 Route and function diagram - temporary use

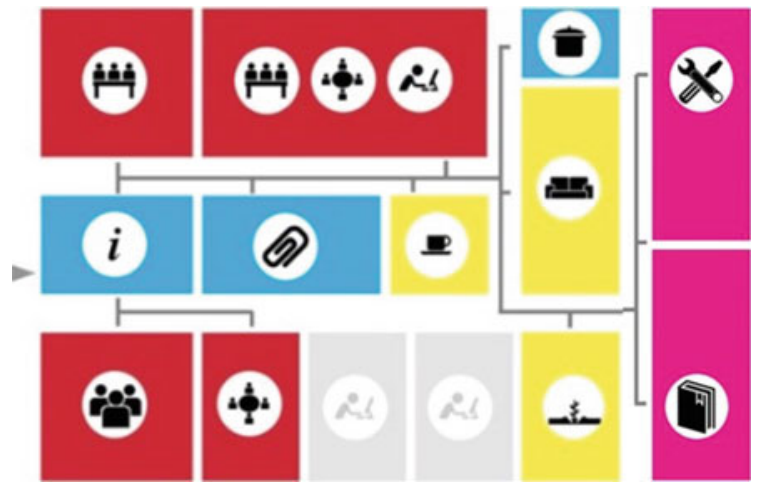

Fig. 3 Route and function diagram-use in the medium term

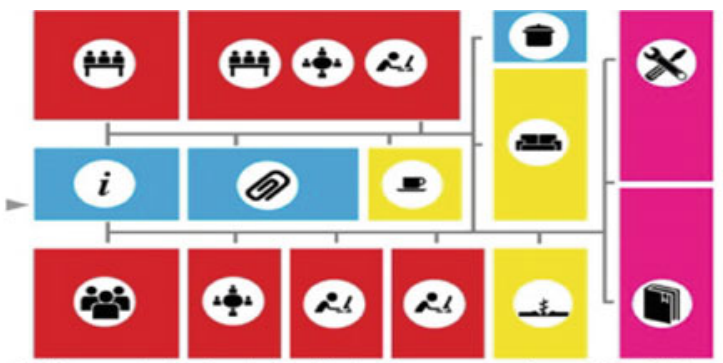

spazi di lavoro (sala riunioni, ufficio openspace, sala studio/ufficio, sala con. gressi)

spazi di servizio (ingresso/reception, cucina, locale stampanti/archivio/magaz. zino, servizi igienici)

spazi ricreativi (area ristoro, spazio relax, spazio esterno)

spazi per servizi supplementari (biblioteca, laboratorio)

Fig. 4 Route and function diagram-long-term use 
continuity over time (e.g., six months a year) have the opportunity to occupy the premises characterized by a greater level of privacy (offices).

The 24-h coworking spaces can be managed in different ways depending on the services offered by the platform. A basic operation is foreseen with daytime opening times from 7 am to $8 \mathrm{pm}$ with the possibility of evening openings on certain occasions (exhibitions, events, meetings, etc.). A second management mode allows for the use of the spaces $24 \mathrm{~h}$ a day to allow access to workstations and to different services even at night.

The study saw the predisposition of a pre-dimensioning matrix that linked both the minimum reference surfaces with the maximum number of users that can be hosted and the percentage weight of a function in relation to the total surface. The reading of the matrix has revealed a number of observations regarding the surfaces: the extension of the work environments has a constant percentage weight in the different spatial solutions, while the surface of the service spaces decreases in proportion to the increase in the offer of activities. As the extension of coworking increases, the percentage of area used for recreational areas remains constant. Finally, the surfaces dedicated to paths are contained given the prevalent open-space aspect and the need to share the structure's spaces.

As described in the introductory passages, the refunctionalization interventions can constitute an effective response to the many questions of change expressed by the community, and although they are yet to represent a single narrative capable of communicating adequately with administrators, they prove to be a privileged field for the experimentation of models of public-private management of real estate assets and integration between economic activities and cultural and socioeconomic functions (Bacchella et al. 2015). The question of reuse becomes an architectural issue since the identification of the new functions cannot be separated from an evaluation of the architectural, typological, and technological characteristics of the building and the peculiarities that characterize the territorial area of reference. The presence of these endogenous and exogenous factors triggers specific problems: for buildings characterized by cultural values, a conflict is generated between the instances of conservation and transformation due to the inclusion of new activities. At the same time, new settled activities can produce positive effects on the surrounding area if they are able to trigger widespread recovery processes of underused areas or can have negative effects if not effectively managed (De Medici and Pinto 2012).

\section{References}

Bacchella, U., Bollo, A., \& Milella, F. (2015). Riuso e trasformazioni degli spazi a vocazione culturale e creativa: un driver per lo sviluppo, ma a quali condizioni? In Giornale delle Fondazioni, Allemandi.

Baiani, S., \& Cangelli, E. (2012). Valorizzazione e sviluppo sostenibile dei sistemi locali. In Technè n. 03/2012, Valorizzare il patrimonio edilizio pubblico. 
Bolici, R., Leali, G., \& Mirandola, S. (2015). Valorizzazione del patrimonio immobiliare dismesso o sottoutilizzato. Progettare per il coworking, report ricerca. http://www.polo-mantova.polimi.it/ uploads/media/4_02.pdf.

De Medici, S., Pinto, M. R. (2012). Valorizzazione dei beni culturali pubblici e strategie di riuso. In Technè n. 03/2012, Valorizzare il patrimonio edilizio pubblico.

Maineri, M. (2013). Marta Mainieri: Ho inventato (e scritto) Collaboriamo!, per riunire tutti i servizi collaborativi italiani. In Che Futuro!, 28 marzo 2013,

Manzo, R. (2007). Il processo di rivitalizzazione del patrimonio pubblico. In R. Manzo \& G. Tamburini (a cura di), Il patrimonio immobiliare pubblico. Nuovi orizzonti. Il ruolo dell'Agenzia del Demanio, Il Sole24Ore, Milano.

Ottone, F., Calvelli, S., Cocci Grifoni, R., Losco, G., Perriccioli, M., Rossi, M., et al. (2012). Rigenerare le città attraverso la valorizzazione del patrimonio pubblico: tecnologie ambientali e creatività. In Technè n. 03/2012, Valorizzare il patrimonio edilizio pubblico.

Ufficio Internazionale del Lavoro. (2012). "La crisi dell'occupazione giovanile: è il momento di agire. Risoluzione e conclusioni della 101a sessione", in Atti Conferenza Internazionale del Lavoro, Ginevra.

Open Access This chapter is licensed under the terms of the Creative Commons Attribution 4.0 International License (http://creativecommons.org/licenses/by/4.0/), which permits use, sharing, adaptation, distribution and reproduction in any medium or format, as long as you give appropriate credit to the original author(s) and the source, provide a link to the Creative Commons license and indicate if changes were made.

The images or other third party material in this chapter are included in the chapter's Creative Commons license, unless indicated otherwise in a credit line to the material. If material is not included in the chapter's Creative Commons license and your intended use is not permitted by statutory regulation or exceeds the permitted use, you will need to obtain permission directly from the copyright holder.

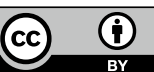

